\title{
Novel transglutaminase 1 mutations in patients affected by lamellar ichthyosis
}

\author{
A Terrinoni ${ }^{1}$, V Serra ${ }^{1}$, A Codispoti ${ }^{1}$ E Talamonti ${ }^{1}$, L Bui ${ }^{1}$, R Palombo ${ }^{2}$, M Sette ${ }^{3}$, E Campione ${ }^{2}$, B Didona ${ }^{4}$, \\ M Annicchiarico-Petruzzelli ${ }^{1}$, G Zambruno ${ }^{4}$, G Melino ${ }^{1}$ and E Candi ${ }^{*, 2}$
}

Lamellar Ichthyosis (LI) is a form of congenital ichthyosis that is caused by mutations in the TGM1 gene that encodes for the transglutaminase 1 (TG1) enzyme. Functional inactivation of TG1 could be due to mutations, deletion or insertions. In this study, we have screened 16 patients affected by LI and found six new mutations: two transition/transversion (R37G, V112A), two nonsense mutations and two putative splice site both leading to a premature stop codon. The mutations are localized in exons 2 (N-terminal domain), 5, 11 (central catalytic domain), and none is located in the two beta-barrel C-terminal domains. In conclusion, this study expands the current knowledge on TGM1 mutation spectrum, increasing the characterization of mutations would provide more accurate prenatal genetic counselling for parents at-risk individuals.

Cell Death and Disease (2012) 3, e416; doi:10.1038/cddis.2012.152; published online 25 October 2012

Subject Category: Experimental Medicine

The epidermis is a multi-layered, stratified epithelium that provides a physical barrier for the organism, protecting it from pathogens and dehydration. ${ }^{1}$ The epidermis is continuously regenerated by terminally differentiated keratinocytes ${ }^{2-7}$ that migrate from the inner basal layer (proliferative compartment) to the outer cornified layer (terminal differentiated compartment): this process is known as cornification, or formation of the cornified envelope. This requires a complex balance between the proliferating compartment, the differentiation compartment and the cornified envelope, which exert its protective barrier function in the epidermis. In addition to this terminal differentiation, another type of cell death occurs in the skin, namely programmed cell death or apoptosis. ${ }^{8-22}$ Apoptosis is a developmental remodelling programme and a defensive, organized self-destruction of the cell in reaction to severe damage.

In several genetic disorders, such as ichthyosis, the corneification process is altered due to mutations in key components of the keratinocyte differentiation machinery. Autosomal recessive congenital ichthyosis (ARCl) is a rare heterogeneous keratinization disorder of the skin. According to the results of the 'First Ichthyosis Consensus Conference' in Sorèze in 2009, in which the nomenclature and classification of inherited ichthyoses has been revised, the disease is clinically and genetically identified including harlequin ichthyosis, lamellar ichthyosis (LI), non-bullous congenital ichthyosiformis and congenital ichthyosiformis. ${ }^{23}$ Valquist $^{24}$ recently also speculated on a new umbrella term for $\mathrm{ARCl}$ disease represented by noticeable phenotypic changing in early childhood and mild, non-LI/non-El skin symptoms remaining into adulthood.
There are seven loci associated to ARCI with five causative genes identified. ${ }^{25}$ These genes code for transglutaminase 1 (TGM1), ${ }^{26,27}$ the adenosine triphosphate binding cassette $12 \mathrm{~A},{ }^{28,29}$ lipoxygenases (ALOXE3, ALOX12B) ${ }^{30}$ and ichtyin (ichtyin or NIPAL4). ${ }^{31,32}$ Patients with the most severe types of ichthyosis show a congenital hyperkeratosis with scales covering a large part of the body's surface. In the LI patients is often present at birth a collodion membrane, covering the neonate, and consisting of shiny taut skin that eventually dries and peels away, leading to the development of large, thick brown scales. Patients with $\mathrm{LI}$ can be either homozygous for single mutations or heterozygous for two different mutations at the same locus.

The first gene associated to the disease has been the TGM1 at chromosome $14 q 11.2^{33,34}$ The TGM1 gene encodes transglutaminase 1 (TG1), which is a member of a class of enzymes that form $N \varepsilon$ - $(\gamma$-glutamyl)lysine or mono- or bis $(\gamma$-glutamyl)spermidine isopeptide bond cross-links between proteins, and it is a calcium-dependent enzyme. ${ }^{1,35}$ The TG1 enzyme is synthesized as an 817 residue polypeptide $(90 \mathrm{kDa})$ and is modified by myristoyl and palitoyl adducts near the $\mathrm{N}$-terminus of the protein. It is expressed in the upper spinous and granular layers beneath the stratum corneum. TG1 is an enzyme important in the formation of the cornified cell envelope, responsible for barrier function in stratified squamous epithelia, by the cross-linking of a variety of structural proteins including desmosomal proteins, involucrin, the small proline-rich proteins, loricrin and trichohyalin. ${ }^{1,36-38}$ It is also reported to crosslink hydroxiceramide during the formation of cornified cell envelope, specifically, omegahydroxyceramides covalently linked by ester bonds to

\footnotetext{
${ }^{1}$ IDI-IRCCS c/o Department of Experimental Medicine and Surgery, University of Tor Vergata, Rome, Italy; ${ }^{2}$ Department of Biology, University of Tor Vergata, Rome, Italy; ${ }^{3}$ Department of Experimental Medicine and Surgery, University of Tor Vergata, Rome, Italy and ${ }^{4}$ IDI-IRCCS, Istituto Dermopatico dell'Immacolata, Via Monti di Creta 104, Rome, Italy

${ }^{*}$ Corresponding author: E Candi, Department of Experimental Medicine and Surgery, University of Tor Vergata, via Montpellier, 1, Rome 00133, Italy. Tel: +39 067259 6487; Fax: +39 067259 6977; E-mail: candi@uniroma2.it

Keywords: transglutaminase 1; keratinocytes; ichthyosis; differentiation; mutation

Abbreviations: TG1, transglutaminase 1; TGM1, gene encoding for TG1; LI, lamellar ichtyosis

Received 21.5.12; revised 27.8.12; accepted 27.8.12; Edited by KA Knight
} 
cornified envelope proteins, most abundantly to involucrin. ${ }^{37}$ The native full-length TG1 protein is proteolysed at two sites during maturation and the three components remain associated in the active membrane-bound form. ${ }^{38}$ The domain spanning from Met-1 to Met-109 represents the pro-peptide portion of the protein, at the end of which is located the most important cleavage site, its cleavage increase the activity of the enzyme $>100$ times, respect to the full-length protein. ${ }^{39}$ The three-dimensional computerized homology model of TG1, based on the factor XIIIa ${ }^{40}$ crystal structure, revealed that the enzyme operate essentially as a dimer. Each monomer has four distinct domains: the amino-terminal $\beta$-sandwich domain (domain 1) from residues Met-109 to Phe-247, codified by exons 2, 3 and 4; the transamidation catalytic core domain (domain 2) from the Ile-255 to Pro-559 (containing the catalytic triade Cys-377; His 336; Asn-459) and two carboxy-terminal $\beta$-barrel domains, which include Glu-577 to Arg-687 (domain 3) and Leu-694 to Gly-800 (domain 4), respectively. Mutations in the TGM1 gene cause defect in the intercellular lipid layers in the stratum corneum, ${ }^{41-43,26,27}$ leading to defective barrier function of the stratum corneum resulting in the ichthyosis phenotype seen in $\mathrm{LI}$ patients ${ }^{44}$ and in the TG1 knockout mice. ${ }^{45}$ The mutations so far described in the literature are mainly localized not only in the catalytic cysteine or in its surrounding region, but also in the $\mathrm{N}$-terminal domain and in the interface between these two domains, suggesting a functional conformational change occurring during catalysis. Mutations in the two $\mathrm{N}$-terminal beta-barrel domains are less frequent, but still present.

The typical clinical features of LI are large, dark grey or large brownish thick scales, covering the entire body surface, including the face. Palmoplantar keratoderma is frequently seen, whereas the hair and the teeth appear normal. Skin manifestations rarely improve with the age. Light microscopy of lesional skin from patients with TGM1-dependent LI show marked hyperkeratosis. The granular layer is normal or mildly increased in thickness. However, in the milder form of $\mathrm{LI}$, the large, dark, lamellar scales can be seen only at the restricted body sites including the trunk, lower legs, upper arms and foreheads. Sometimes the skin on the face and the extremities appears normal and hyperkeratosis is not seen on either the palms or soles. In these milder forms, thin, white to grey scales are sometimes seen on the neck, the extremities and the rest of the body surface. ${ }^{33}$

In this study, we have investigated $60 \mathrm{LI}$ patients and families of Italian origin by mutation analysis of the complete coding sequences of TGM1 gene. We found 22 mutations, distributed in 17 patients $(26 \%$ of the total LI patients investigated), among them, 6 novel and 15 previously described. Some of these mutations are well described and characterized and represent a wide spectrum of characteristic mutations found in LI associated to TG1.

\section{Results}

Clinical and genetic analysis. We have screened 60 patients that were diagnosed as LI. Large parts of the probands showed the classical LI phenotypes with large brown and thick scales covering the entire body surface, born as collodion baby (patient 1, 2, 3, 4, 6, 7, 8, 9, 8, 10, 11, 12, $13,14,15,16,17)$, even if a wide gradient in disease severity had been observed, as described in Table 1. The results of the genetics analysis in Ichthyosis patients are also represented in Table 1 . The sequence analysis of the TG1 patients showed the presence of new and known mutations in TGM1 gene in about $26 \%$ of them, thus confirming the heterogeneity of genetic inheritance of the disease. Regarding the mutations, they can be classified into three different subgroups: missense mutation leading to amino-acid substitutions, nonsense mutations causing the transition of a codifying codon into a stop codon and insertion/deletion mutations, that modify the reading frame of the coding region and/or the donor/acceptor splice sites. Regarding the new mutations found in homozygousity in patients (see below), they cannot be considered sporadic 'de novo' mutations, because there is no report of consanguinity in the family. Probably, the mutated alleles are present in very low frequency in the areas in which these patients reside. In the first group we found eight mutations caused by single-nucleotide transition/transversion, two of them are new mutations never described up to now. The new mutations found are: the R37G, found in patient 9 and located in exon 2, codifying for the pro-peptide region and the $\mathrm{V} 112 \mathrm{~A}$ found in patient 11 located at the beginning of the $\mathrm{N}$-terminal beta-sandwich domain (Figure 1). The other known mutations of the first type found in the IL patients analysed are: G473S found in patient 1 and located in exon 10 , codifying the end of the catalytic core domain; ${ }^{45} \mathrm{R} 142 \mathrm{H}$ (patient 4), located in exon $3 ;^{26} \mathrm{~S} 272 \mathrm{P}$ (patient 5) in exon $5 ;{ }^{47}$ V383M in exon 7.48 E520G (patient 8) located in the exon11; ${ }^{47} \mathrm{R} 315 \mathrm{H}$ (patient 10), located in the exon $6,{ }^{49}$ V379L (patient 17), located in exon $7 ;^{26}$ see Table 1 for further details. Among the nonsense mutations, we found four single-nucleotide transitions, all giving rise to stop codons and truncated proteins, the already known R54X (patient 2), R348X (patient 17), and the two new mutations W263X (patient 3) and S550X (patient 11). The first mutation, R54X truncates the enzyme in the second exon, presumably in this case there is the absence of a translation product due to the reduced size of the mRNA. In W263X mutant the enzyme ends at the level of exon 5, and the R348X in exon 7, both resulting in the loss of catalytic triade. The S550X mutants is also C-terminal truncated, it contains the active site but lacks the beta-barrel 1 and 2 domains, important for TG1 activity (Figure 1). In addition, in patient 9 we found an heterozygous mutation analysing the RNA. We discovered the deletion c.1465_1492del giving rise to the Y489X nonsense mutation again generating a truncated enzyme lacking the beta-barrel 1 and 2 domains. In patient 6 , we also found a deletion mutation in the last 26 residues of intron 5 (c.851_877del), leading to the insertion of the residual part of the intron 5 in the coding sequence, resulting in the formation of a premature stop codon (Figure 1). It is interesting to note from this study that the most frequent mutation found in Italian IL patients bearing TG1 mutations is splicing error giving rise to intron insertion and consequent frame shift and premature stop codon formation (homozygous mutation in patients $12-16$ and heterozygous mutation in patients 7 ). 
|

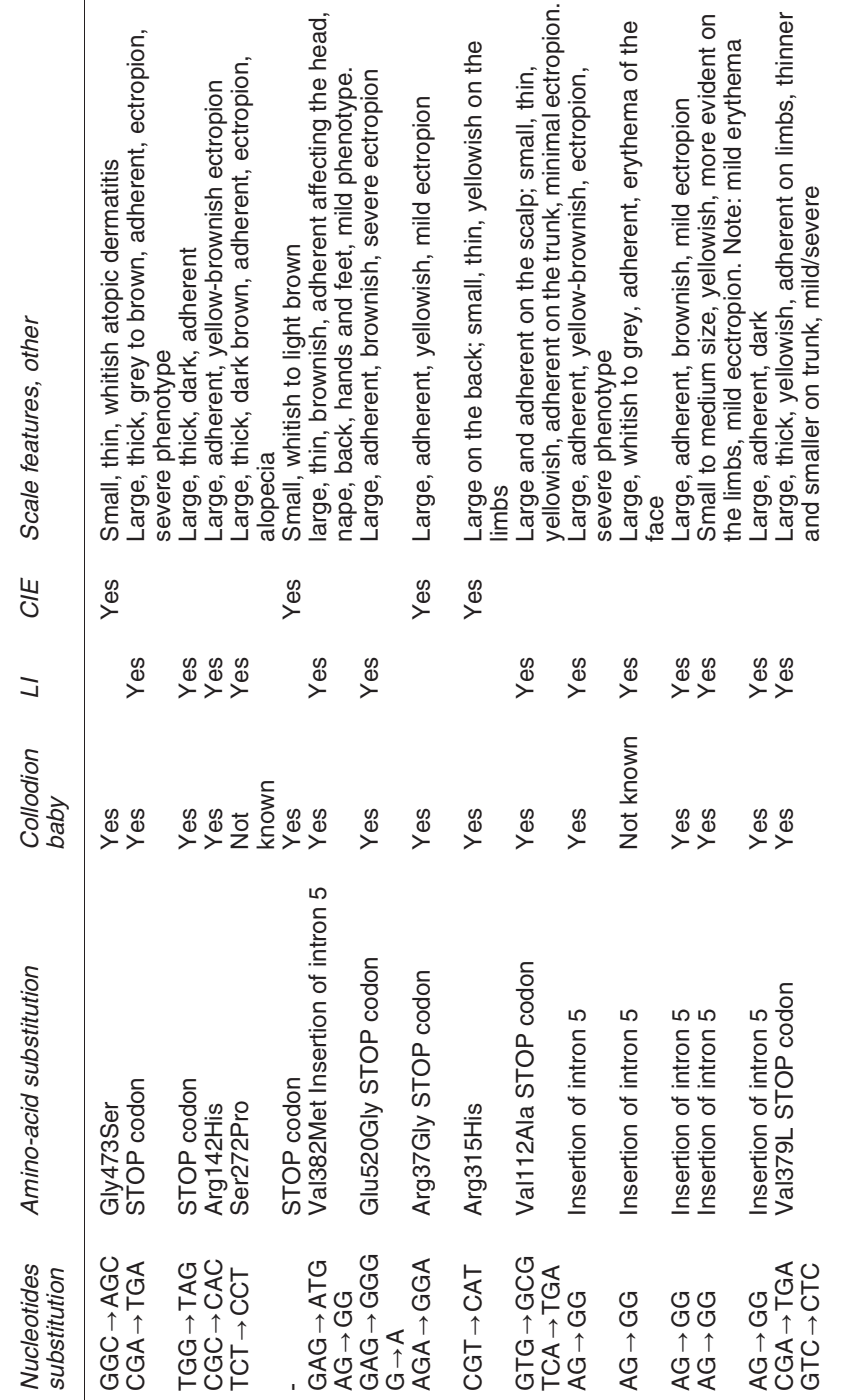

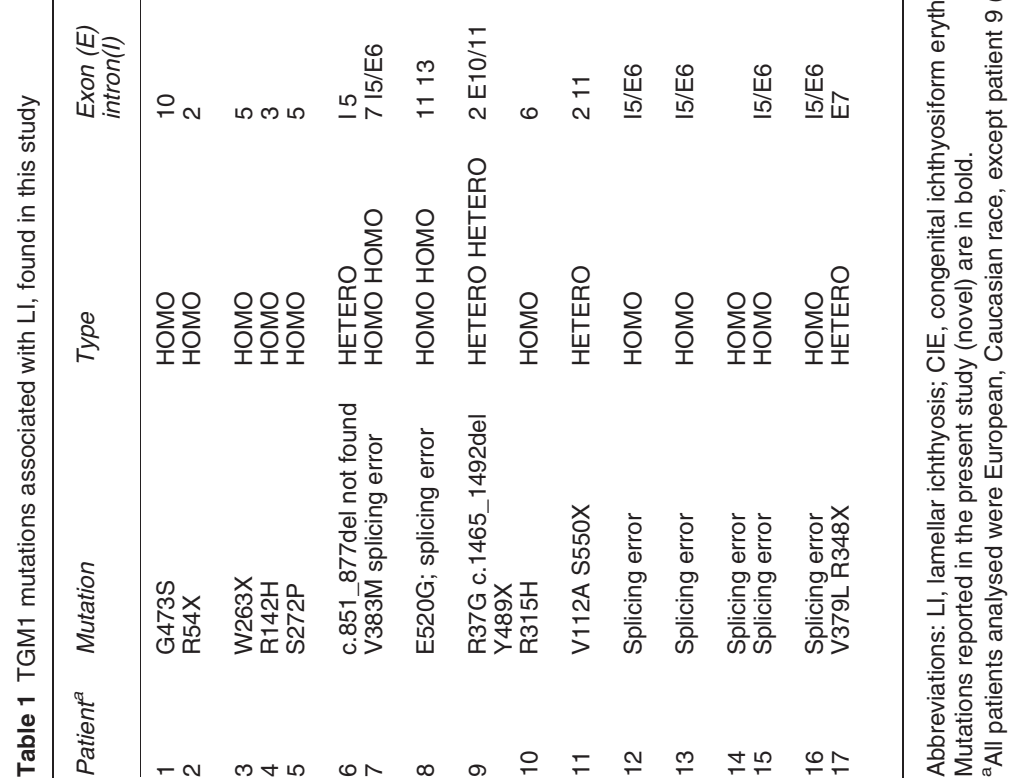



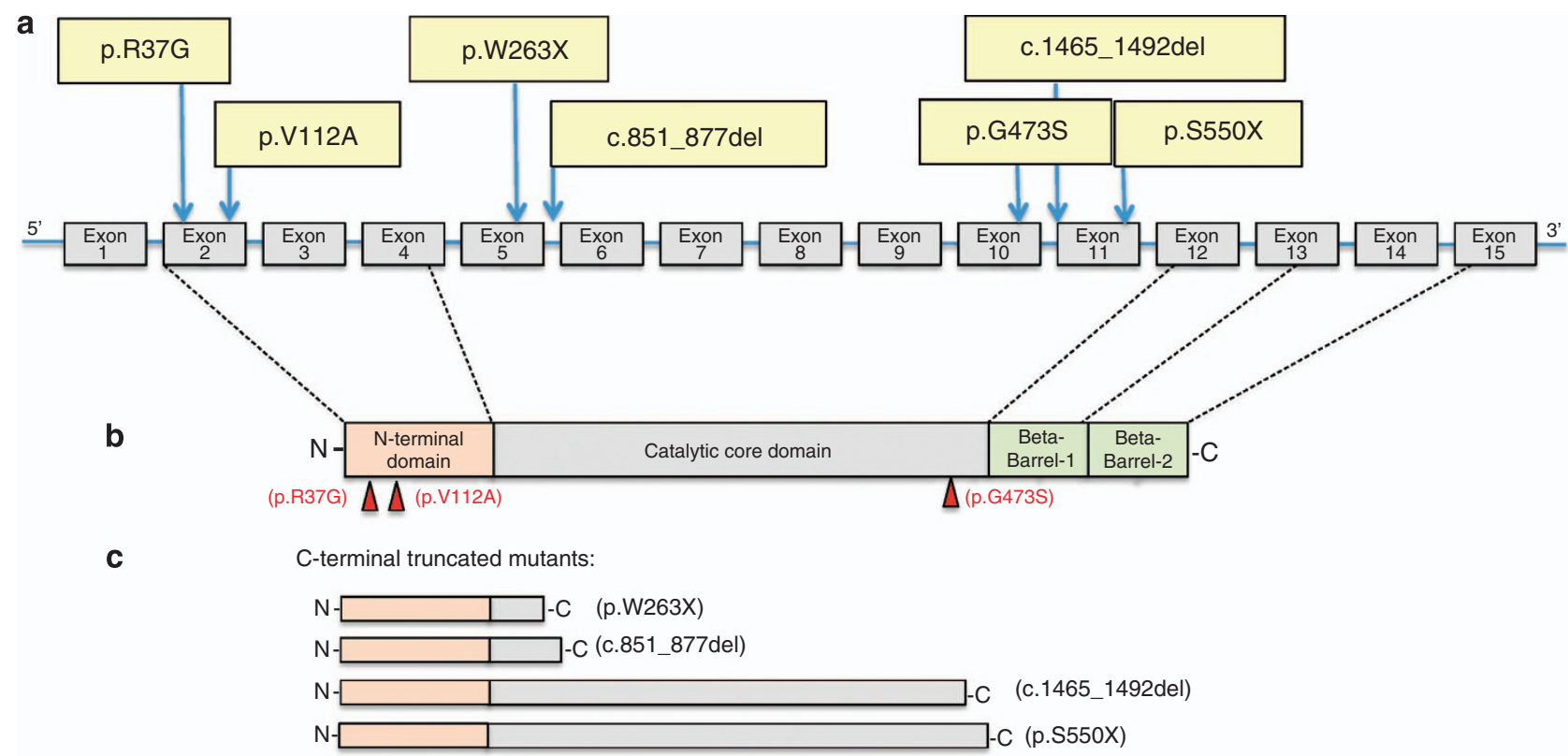

Figure 1 Novel TGM1 mutations associated with lamellar icthyosis. (a) Novel TGM1 mutations reported in this study and their localization in the gene structure. (b) Single amino-acid substitutions are indicated in relationship to the TG1 domains. (c) Missense mutations generated truncated enzyme lacking beta-barrel 1 and 2 domains and catalityc domain (p.W263X, c.851_877del).

\section{Conclusion}

Several previous studies have attempted to demonstrate the existence of genotype-phenotype correlations between mutation in TG1 and clinical and/or ultra structural findings of the patient skins. However, there is a strong variability in clinical features of patients with the same mutation and there is not a clear association between the TG1 domain affected by the mutation and the severity of the phenotype. Our work, together with other studies, contribute to the identification of a large number of mutations with the aim to simplify the challenge in confirming the clinical diagnosis of patients affected by LI. Despite the genetic heterogeneity of this disease, TG1 has been the causative gene identified most often ${ }^{25,46}$ and consequently the first gene to be analysed to screen for mutations, expanding the mutations spectrum will facilitate the understanding of genetic, molecular and pathophysiological aspect of $\mathrm{LI}$. In addition, although the mutations found are distributed along all the gene sequence, we can observe among italian patients a clear founder effect regarding the intron5/exon6 splice site mutation. Our results could enhance our understanding in the pathogenesis of icthyosis and will be useful for new therapeutic approach also for the phenotypic shifts of ARCI.

\section{Materials and Methods \\ Collection of clinical material and DNA isolation. Genomic DNA samples were extracted from patient blood and from the other family members according to standard procedures. ${ }^{50}$ This work was approved in the institutional ethics committee, at IDI-IRCCS, Istituto Dermopatico dell'Immacolata, Rome. The authors obtained informed consent from patients who provided their specimens.}

PCR and RT-PCR amplification of TGM1 and DNA sequencing. Reverse transcription was performed using the Superscript-II reverse transcriptase
(Life Technologies Ltd, Paisley, UK), with $100 \mathrm{ng}$ of total RNA using $10 \mathrm{pmol}$ of oligo dT primers, buffer and enzyme concentrations according to the manufacturer instructions. The entire coding region of the TGM1 gene was PCR amplified using $0.4 \mu \mathrm{m}$ of primer $5^{\prime}-$ CTCCCTCCCACATAAGTCAC-3', for $(+)$ strand and $5^{\prime}$-TAG CATCTGTTCCCCCAGTGCAAGTGAAG- $3^{\prime}$, for $(-)$ strand, designed from the published cDNA sequences. PCR fragments were resolved on $0.8 \%$ agarose gel (TAE), extracted and purified using the Qiaex II extraction kit (Qiagen, Valencia, CA, USA). Approximately $100 \mathrm{ng}$ of purified template DNA was automatically sequenced with the BigDye Termination Reaction Kit (Applied Biosystem, Carlsbad, CA, USA) on an ABI-PRISM 377 DNA sequencer (Applied Biosystem), using internal primers. In patients for whom the RNA was not available, the coding region has been amplified using intronic primers flanking exons.

\section{Conflict of Interest}

The authors declare no conflict of interest.

Acknowledgements. This work has been supported by Telethon Grant GGP06048, to EC and partially supported by IDI-IRCCS (RF06 c.73, RF07 c.57, RF08 c.15, RF07 c.57) to GM and EC.

1. Candi E, Schmidt R, Melino G. The cornified envelope: a model of cell death in the skin. Nat Rev Mol Cell Biol 2005; 6: 328-340.

2. Alameda $P$, Fernández-Aceñero MJ, Moreno-Maldonado R, Navarro M, Quintana $R$, Page $A$ et al. CYLD regulates keratinocyte differentiation and skin cancer progression in humans. Cell Death Dis 2011; 2: e208.

3. Hara T, Miyazaki M, Hakuno F, Takahashi S, Chida K. PKC $\eta$ promotes a proliferation to differentiation switch in keratinocytes via upregulation of p27Kip1 mRNA through suppression of JNK/c-Jun signaling under stress conditions. Cell Death Dis 2011; 2: e157.

4. Barton CE, Johnson KN, Mays DM, Boehnke K, Shyr Y, Boukamp P et al. Novel p63 target genes involved in paracrine signaling and keratinocyte differentiation. Cell Death Dis 2010; 1: e74.

5. Straub WE, Weber TA, Schäfer B, Candi E, Durst F, Ou HD et al. The C-terminus of p63 contains multiple regulatory elements with different functions. Cell Death Dis 2010; 1: e5.

6. Royer C, Lu X. Epithelial cell polarity: a major gatekeeper against cancer? Cell Death Differ 2011; 18: 1470-1477.

7. Yi R, Fuchs E. MicroRNA-mediated control in the skin. Cell Death Differ 2010; 17: 229-235. 
8. Kober AM, Legewie S, Pforr C, Fricker N, Eils R, Krammer PH et al. Caspase-8 activity has an essential role in CD95/Fas-mediated MAPK activation. Cell Death Dis 2011; 6: e212.

9. Badmann A, Keough A, Kaufmann T, Bouillet P, Brunner T, Corazza N. Role of TRAIL and the pro-apoptotic $\mathrm{Bcl}-2$ homolog Bim in acetaminophen-induced liver damage. Cell Death Dis 2011; 2: e171.

10. Yivgi-Ohana N, Eifer M, Addadi Y, Neeman M, Gross A. Utilizing mitochondrial events as biomarkers for imaging apoptosis. Cell Death Dis 2011; 2: e166.

11. Rosati A, Graziano V, De Laurenzi V, Pascale M, Turco MC. BAG3: a multifaceted protein that regulates major cell pathways. Cell Death Dis 2011; 2: e141.

12. Graber TE, Holcik M. Distinct roles for the cellular inhibitors of apoptosis proteins 1 and 2 Cell Death Dis 2011; 2: e135.

13. Cheng JP, Betin VM, Weir H, Shelmani GM, Moss DK, Lane JD. Caspase cleavage of the Golgi stacking factor GRASP65 is required for Fas/CD95-mediated apoptosis. Cell Death Dis 2010; 1: e8.

14. Fricker M, O'Prey J, Tolkovsky AM, Ryan KM. Phosphorylation of Puma modulates its apoptotic function by regulating protein stability. Cell Death Dis 2010; 1: e59.

15. Chan KS, Wong CH, Huang YF, Li HY. Survivin withdrawal by nuclear export failure as a physiological switch to commit cells to apoptosis. Cell Death Dis 2010; 1: e57.

16. Flanagan L, Sebastià J, Tuffy LP, Spring A, Lichawska A, Devocelle M et al. XIAP impairs Smac release from the mitochondria during apoptosis. Cell Death Dis 2010; 1: e49.

17. Tomlinson V, Gudmundsdottir K, Luong P, Leung KY, Knebel A, Basu S. JNK phosphorylates Yes-associated protein (YAP) to regulate apoptosis. Cell Death Dis 2010; 1: $\mathrm{e} 29$

18. Mitchell G, Fillinger J, Sittadjody S, Avila J, Burd R, Limesand K. IGF1 activates cell cycle arrest following irradiation by reducing binding of $\Delta \mathrm{Np} 63$ to the p21 promoter. Cell Death Dis 2010; 1: e50.

19. Burnstock G, Verkhratsky A. Long-term (trophic) purinergic signalling: purinoceptors control cell proliferation, differentiation and death. Cell Death Dis 2010; 1: e9.

20. Knight RA, Melino G. Cell death in disease: from 2010 onwards. Cell Death Dis 2011; 2 e202.

21. Melino G. p63 is a suppressor of tumorigenesis and metastasis interacting with mutant p53. Cell Death Differ 2011; 18: 1487-99.

22. Geering B, Simon HU. Peculiarities of cell death mechanisms in neutrophils. Cell Death Differ 2011; 18: 1457-69.

23. Oji V, Tadini G, Akiyama M, Blanchet Bardon C, Bodemer C et al. Revised nomenclature and classification of inherited ichthyoses: results of the First Ichthyosis Consensus Conference in Soreze 2009. J Am Acad Dermatol 2010; 63: 607-641.

24. Vahlquist $A$, Bygum $A$, Gånemo $A$, Virtanen $M$, Hellström-Pigg $M$, Strauss $G$ et al. Genotypic and clinical spectrum of self-improving collodion ichthyosis: ALOX12B, ALOXE3, and TGM1 mutations in Scandinavian patients. J Invest Dermatol 2010; 130: 438-43.

25. Akiyama M. Harlequin ichthyosis and other autosomal recessive congenital ichthyoses: the underlying genetic defects and pathomechanisms. J Dermatol Sci 2006; 42 : 83-89.

26. Huber M, Rettler I, Bernasconi K, Frenk E, Lavrijsen SP, Ponec M et al. Mutations of keratinocyte transglutaminase in lamellar ichthyosis. Science 1995; 267: 525-528.

27. Russell LJ, DiGiovanna JJ, Rogers GR, Steinert PM, Hashem N, Compton JG et a. Mutations in the gene for transglutaminase 1 in autosomal recessive lamellar ichthyosis. Nat Genet 1995; 9: 279-283.

28. Annilo T, Shulenin S, Chen ZQ, Arnould I, Prades C, Lemoine $C$ et al. Identification and characterization of a novel $A B C A$ subfamily member, $A B C A 12$, located in the lamellar ichthyosis region on 2q34. Cytogenet Genome Res 2002; 98: 169-176.

29. Lefevre C, Audebert S, Jobard F, Bouadjar B, Lakhdar H, Boughdene-Stambouli O et al. Mutations in the transporter $\mathrm{ABCA} 12$ are associated with lamellar ichthyosis type 2 Hum Mol Genet 2003; 12: 2369-2378.

30. Jobard F, Lefevre C, Karaduman A, Blanchet-Bardon C, Emre S, Weissenbach J et al. Lipoxygenase-3 (ALOXE3) and 12(R)-lipoxygenase (ALOX12B) are mutated in non-bullous congenital ichthyosiform erythroderma (NCIE) linked to chromosome 17p13.1. Hum Mol Genet 2002; 11: 107-113.

31. Lefevre C, Bouadjar B, Karaduman A, Jobard F, Saker S, Ozguc M et al. Mutations in ichthyin a new gene on chromosome $5 \mathrm{q} 33$ in a new form of autosomal recessive congenital ichthyosis. Hum Mol Genet 2004; 13: 2473-2482.
32. Williams ML, Elias PM. Heterogeneity in autosomal recessive ichthyosis. Clinical and biochemical differentiation of lamellar ichthyosis and nonbullous congenital ichthyosiform erythroderma. Arch Dermatol 1985; 121: 477-488.

33. Laiho E, Niemi KM, Ignatius J, Kere J, Palotie A, Saarialho-Kere U. Clinical and morphological correlations for transglutaminase 1 gene mutations in autosomal recessive congenital ichthyosis. Eur J Hum Genet 1999; 7: 625-632

34. Russell LJ, DiGiovanna JJ, Hashem N, Compton JG, Bale SJ. Linkage of autosomal recessive lamellar ichthyosis to chromosome 14q. Am J Hum Genet 1994; 55: 1146-1152.

35. Kim IG, McBride OW, Wang M, Kim SY, Idler WW, Steinert PM. Structure and organization of the human transglutaminase 1 gene. J Biol Chem 1992; 267: 7710-7717.

36. Marekov LN, Steinert PM. Ceramides are bound to structural proteins of the human foreskin epidermal cornified cell envelope. J Biol Chem 1998; 273: 17763-17770.

37. Nemes Z, Marekov LN, Fesus L, Steinert PM. A novel function for transglutaminase 1: attachment of long-chain omega-hydroxyceramides to involucrin by ester bond formation Proc Natl Acad Sci USA 1999; 96: 8402-8407.

38. Steinert PM, Kim SY, Chung SI, Marekov LN. The transglutaminase 1 enzyme is variably acylated by myristate and palmitate during differentiation in epidermal keratinocytes. J Biol Chem 1996; 271: 26242-26250.

39. Kim SY, Chung SI, Steinert PM. Highly active soluble processed forms of the transglutaminase 1 enzyme in epidermal keratinocytes. J Biol Chem 1995; 270: 18026-18035.

40. Yee VC, Pedersen LC, Le Trong I, Bishop PD, Stenkamp RE, Teller DC. Threedimensional structure of a transglutaminase: human blood coagulation factor XIII. Proc Natl Acad Sci USA 1994; 91: 7296-7300.

41. Candi E, Melino G, Lahm A, Ceci R, Rossi A, Kim IG et al. Transglutaminase 1 mutations in lamellar ichthyosis. Loss of activity due to failure of activation by proteolytic processing. J Biol Chem 1998; 273: 13693-13702.

42. Candi E, Melino G, Mei G, Tarcsa E, Chung SI, Marekov LN et al. Biochemical, structural, and transglutaminase substrate properties of human loricrin, the major epidermal cornified cell envelope protein. J Biol Chem 1995; 270: 26382-26390.

43. Candi E, Tarcsa E, Idler WW, Kartasova T, Marekov LN, Steinert PM. Transglutaminase cross-linking properties of the small proline-rich 1 family of cornified cell envelope proteins. Integration with loricrin. J Biol Chem 1999; 274: 7226-7237.

44. Elias PM, Schmuth M, Uchida Y, Rice RH, Behne M, Crumrine D et al. Basis for the permeability barrier abnormality in lamellar ichthyosis. Exp Dermatol 2002; 11: 248-256.

45. Huber M, Yee VC, Burri N, Vikerfors E, Lavriisen AP, Paller AS et al. Consequences of seven novel mutations on the expression and structure of keratinocyte transglutaminase. J Biol Chem 1997; 272: 21018-26.

46. Kuramoto N, Takizawa T, Takizawa T, Matsuki M, Morioka H, Robinson JM et al. Development of ichthyosiform skin compensates for defective permeability barrier function in mice lacking transglutaminase 1. J Clin Invest 2002; 109: 243-250.

47. Esposito G, Auricchio L, Rescigno G, Paparo F, Rinaldi M, Salvatore F. Transglutaminase 1 gene mutations in Italian patients with autosomal recessive lamellar ichthyosis. J Invest Dermatol 2001; 116: 809-12.

48. Petit E, Huber M, Rochat A, Bodemer C, Teillac-Hamel D, Müh JP et al. Three novel point mutations in the keratinocyte transglutaminase (TGK) gene in lamellar ichthyosis: significance for mutant transcript level, TGK immunodetection and activity. Eur J Hum Genet 1997; 5: 218-28.

49. Herman ML, Farasat S, Steinbach PJ, Wei MH, Toure O, Fleckman $\mathrm{P}$ et al. Transglutaminase-1 gene mutations in autosomal recessive congenital ichthyosis: summary of mutations (including 23 novel) and modeling of TGase-1. Hum Mutat 2009; 30: $537-47$.

50. Sambrook J, Russel D. Cold Stprig Harbor. Cold Spring Harbor Laboratory Press: New York, 2001.

Cell Death and Disease is an open-access journal published by Nature Publishing Group. This work is licensed under the Creative Commons Attribution-NonCommercial-No Derivative Works 3.0 Unported License. To view a copy of this license, visit http://creativecommons.org/licenses/by-nc-nd/3.0/ 